\title{
Indian Academy of Sciences (Bangalore), Indian National Science Academy (New Delhi) and the National Academy of Sciences, India (Allahabad) Joint Programme
}

Three National Science Academies' Lecture Workshop on Plane Geometry to RubberSheet Geometry was held on June 29-30, 2012 at NASI, Allahabad, as per following schedule

(C) The National Academy of Sciences, India 2012

Programme of Lectures/Interactions: Ist Day (June 29, 2012)

10:00-11:30 am, Lecture

Dr. V. Pati, ISI, Bangalore on "Quaternions and rotations in 3-space"

12:00-13:30 pm, Lecture

Dr. C.S. Arvinda, TIFR Bangalore Center, on "Euclid, regular solids and a journey through to non-Euclidean geometry"

14:30-16:00 pm, Lecture

Prof. S.S. Khare, NEHU, Shillong, on "From Euclidean geometry to non-Euclidean geometry with special focus to taxicab geometry"

16:30-17:00 pm, Interactive and problem solving session Prof. Satya Deo, C.S. Arvinda, S.S. Khare.
Programme of Lectures/Interactions: IInd Day (June 30, 2012)

10:00-11:30 am, Lecture

Prof. Satya Deo, HRI, Allahabad on "Historical motivations of rubber sheet geometry"

12:00-13:30 pm, Lecture

Prof. Ramji Lal, IIIT, Allahabad on "Introducing hyperbolic geometry"

14:30-16:00 pm, Interactive and problem solving session Prof. Satya Deo, Ramji Lal, V. Pati.

16:00-17:00 pm, Valedictory

The convener of the programme was Prof Satya Deo; and coordinator was Dr Niraj Kumar. 